\title{
Flocos desidratados de abóbora na prevenção da carência de vitamina $A$ em pré-escolares de uma creche
}

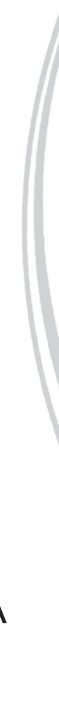

\author{
Dehydrated pumpkin flakes for preventing \\ vitamin A deficiency in preschoolers \\ attending a daycare
}

Carmem Lygia Burgos AMBRÓSIO'

Florisbela de Arruda Camara e Siqueira CAMPOS²

Zelyta Pinheiro de FARO'

Hernando FLORES (in memoriam) ${ }^{3}$

Maria Helena de Castro CHAGAS $^{3}$

Raquel Araújo de SANTANA ${ }^{3}$

\section{RE S U M O}

\section{Objetivo}

Esta pesquisa teve como objetivo avaliar a eficácia de flocos desidratados de abóbora na elevação dos níveis séricos de retinol e a resposta relativa à dose em pré-escolares.

\section{Métodos}

A ingestão de vitamina A foi avaliada por meio de inquérito dietético. Os flocos foram analisados quanto às características microbiológicas e ao conteúdo de carotenoides. As crianças estudadas receberam diariamente $6 \mathrm{~g}$ do produto no almoço, durante 90 dias. Elas foram submetidas ao teste de resposta relativa à dose no início e no final do estudo. Amostras de sangue foram colhidas em jejum, para análise do retinol sérico por espectrofotometria, no início do estudo, aos 30 dias de consumo e aos 90 dias.

\section{Resultados}

Quanto às análises microbiológicas, os flocos encontravam-se adequados para consumo. O nível médio de retinol sérico nas crianças aumentou de $M=1,438, D P=0,45 \mu \mathrm{mol} / \mathrm{L}$ (tempo 0) para $M=1,659, D P=0,51 \mu \mathrm{mol} / \mathrm{L}$ (30 dias) e $\mathrm{M}=1,928, \mathrm{DP}=0,70 \mu \mathrm{mol} / \mathrm{L}$ (90 dias). No início do estudo, 18,5\% das crianças apresentavam níveis

\footnotetext{
1 Universidade Federal de Pernambuco, Centro Acadêmico de Vitória, Núcleo de Nutrição. R. Alto do Reservatório, s/n., Bela Vista, 55608-680, Vitória de Santo Antão, PE, Brasil. Correspondência para/Correspondence to: CLB AMBRÓSIO. E-mail: <carmem.burgos@hotmail.com>.

${ }^{2}$ Universidade Federal de Pernambuco, Centro Acadêmico de Vitória, Núcleo de Educação Física e Ciências do Esporte. Vitória de Santo Antão, PE, Brasil.

${ }^{3}$ Universidade Federal de Pernambuco, Centro de Ciências da Saúde, Departamento de Nutrição. Recife, PE, Brasil.
} 
58 | CLB AMBRÓSIO et al.

de retinol sérico abaixo do ponto de corte de 1,05 $\mathrm{mol} / \mathrm{L}$, proporção que caiu para 7,6\% depois de 30 dias e para $0 \%$ após 90 dias. No final do período de estudo (90 dias) nenhuma criança apresentou resposta relativa à dose positiva.

\section{Conclusão}

Os flocos de abóbora são eficazes na elevação do retinol sérico e na reserva hepática da vitamina em pré-escolares.

Termos de indexação: Carotenoides. Cucurbita. Deficiência de vitamina. Flocos desidratados. Retinol sérico. Vitamina A.

\section{A B S T R A C T}

\section{Objective}

This study assessed the effectiveness of dehydrated pumpkin flakes for elevating serum retinol and the relative dose response in preschoolers.

\section{Methods}

Vitamin A intake was determined by dietary survey. The flakes were analyzed microbiologically and for carotenoid content. The children were then given 6 grams of flakes per day during lunch for 90 days. The relative dose response essay was done at baseline and end of intervention. Fasting blood samples were collected at baseline, 30 and 90 days to determine serum retinol levels by spectrophotometry.

\section{Results}

Microbiological analyses showed that the flakes were suitable for consumption. The mean serum retinol level of the children increased from $M=1.438$ (SD=0.45 $\mathrm{mol} / \mathrm{L}$ ) at baseline to $M=1.659$ (SD=0.51 $\mu \mathrm{mol} / \mathrm{L})$ at 30 days and $M=1.928$ (SD=0.70 $\mathrm{mmol} / \mathrm{L})$ at 90 days. At the beginning of the study, $18.5 \%$ of the children had serum retinol levels below $1.05 \mu \mathrm{mol} / \mathrm{L}$. This percentage dropped to $7.6 \%$ after 30 days and $0 \%$ after 90 days. At the end of the study period (90 days), no child had a positive relative dose response.

\section{Conclusion}

Pumpkin flakes efficiently increase serum retinol levels and hepatic vitamin A reserves in preschoolers.

Indexing terms: Carotenoids. Cucurbita. Avitaminosis. Dehydrated flakes. Serum retinol. Vitamin A.

\section{N T R O D U ÇÃ O}

A deficiência de vitamina A é um dos principais problemas de saúde pública e afeta milhares de crianças em países em desenvolvimento, como o Brasil, causando cegueira noturna e nutricional irreversível, bem como elevadas taxas de morbidade e mortalidade infantil'.

Nos países em desenvolvimento, é baixo o consumo de alimentos de origem animal, em decorrência do seu alto custo e do baixo poder aquisitivo da população. Estima-se que as provitaminas vegetais constituam a maior porção das vitaminas dietéticas, podendo chegar a $88 \%$ nesses países².

Pesquisas sugerem que os atuais fatores de conversão da vitamina A ( $1 \mathrm{RE}=1 \mu \mathrm{g}$ retinol/
$12 \mu \mathrm{g}$ de $\beta$-caroteno/ $24 \mu \mathrm{g}$ de outros carotenoides precursores de vitamina A) são superiores às antigas recomendações ( $1 \mathrm{RE}=1 \mu \mathrm{g}$ retinol/ $6 \mu \mathrm{g}$ de $\beta$-caroteno/ $12 \mu \mathrm{g}$ de outros carotenoides precursores de vitamina A), o que implica uma efetividade ainda menor na conversão dos carotenoides em retinol ${ }^{3-7}$.

Embora os atuais fatores de conversão sugiram uma limitada biodisponibilidade dos carotenoides, alguns estudos mostram que é possível reverter a deficiência de vitamina $A$ por meio do consumo de vegetais ricos em provitamina $A^{8,9}$.

A abóbora é uma fonte de carotenoides que vem sendo estudada em razão de seu uso em uma ampla variedade de produtos alimentícios ${ }^{10,11}$. A utilização desse alimento na forma 
de flocos garante maior controle microbiológico, melhor conservação e maior facilidade de transporte. Outras fontes vegetais de provitamina $A$ que também são utilizadas na forma de flocos, como a batata doce (Ipomoea batata), já foram testadas quanto à estabilidade e biodisponibilidade dos carotenoides ${ }^{12-14}$.

O presente estudo avaliou a eficácia de flocos desidratados de abóbora na elevação dos níveis séricos de retinol e na recuperação das reservas hepáticas de vitamina $A$, em pré-escolares de ambos os sexos, com idade entre 12 e 72 meses.

\section{M É T O D O S}

\section{Flocos desidratados de abóbora}

Duas diferentes espécies de abóbora foram utilizadas para a elaboração dos flocos: Cucurbita maxima e Cucurbita moschata, comercializadas em mercados da região metropolitana da cidade de Recife (PE), Brasil. Após a aquisição, os frutos foram transportados para o Laboratório de Experimentação e Análise de Alimentos Nonete Barbosa Guerra, do Departamento de Nutrição da Universidade Federal de Pernambuco, para o processamento e análises laboratoriais.

Os flocos foram obtidos por processo de secagem ${ }^{15,16}$, e avaliados quanto às características microbiológicas por meio de análises de coliformes a $45^{\circ} \mathrm{C}$, Escherichia coli, Staphylococcus aureus, Salmonela sp., contagem de bolores e leveduras e conteúdo de carotenoides ${ }^{17,18}$.

Como embalagem primária foram utilizados sacos de polietileno com $26,8 \mathrm{~cm} \times 27,9 \mathrm{~cm}$. Antes do fechamento, os flocos foram submetidos a um jato de nitrogênio por aproximadamente 1 minuto. Posteriormente, foram colocados em caixas de papelão comum e conduzidos para a creche, para que fossem consumidos durante o almoço. O tempo transcorrido entre a elaboração do produto e a oferta dos flocos na alimentação foi de uma semana.
Cada criança recebeu diariamente $6 \mathrm{~g}$ de flocos desidratados (400 $\mu \mathrm{g}$ de vitamina A - quantidade diária máxima permitida) ${ }^{3}$, adicionados ao pirão, molho de macarrão ou feijão oferecidos na creche durante o almoço. As preparações foram consumidas de segunda a sexta-feira. A ingestão dos flocos foi acompanhada diariamente, assim como a frequência das crianças à creche.

A quantidade de $6 \mathrm{~g}$ foi estabelecida de acordo com os seguintes fatores levados em consideração para o enriquecimento: a atual recomendação diária de vitamina $\mathrm{A}(400 \mu \mathrm{g})$, a conversão de $\beta$-caroteno em retinol (1:12), o valor Médio (M) de carotenoides dos flocos de 107,08mg\%, Desvio-Padrão (DP) $=31,29 \mathrm{mg} \%$, o fato de que cerca de $80 \%$ dos carotenoides da abóbora são do tipo $\beta$-caroteno e o índice de rejeito de $10 \%$ dos alimentos oferecidos ${ }^{3}$.

Os flocos de abóbora foram adicionados às preparações citadas quando elas já se encontravam devidamente cozidas, evitando dessa forma que eles fossem submetidos ao processo de cocção. O consumo de flocos desidratados de abóbora acrescentados às refeições ocorreu durante os 90 dias do estudo.

Para avaliar a aceitabilidade dos flocos nas preparações, foi calculado o índice de rejeito, pesando-se a quantidade total de alimentos oferecidos antes e após o almoço, em quatros diferentes medidas ${ }^{19}$.

O trabalho foi aprovado pelo Comitê de Ética em Pesquisa Envolvendo Seres Humanos, do Centro de Ciências da Saúde da Universidade Federal de Pernambuco (Protocolo de Pesquisa $n^{\circ}$ 072/2002).

Participaram da pesquisa 97 crianças de uma comunidade carente, situada nas proximidades do campus da Universidade Federal de Pernambuco, cadastradas em uma creche da Prefeitura da Cidade do Recife, de ambos os sexos, com idade entre 12 e 72 meses.

Após receberem toda a informação necessária referente à participação das crianças na pesquisa, os pais ou responsáveis legais assinaram um termo de consentimento livre e esclarecido. 


\section{Avaliação dietética}

A composição das refeições oferecidas na creche é planejada pela Prefeitura da Cidade do Recife, e as crianças recebem três refeições, de segunda a sexta-feira. O conteúdo de micronutrientes da merenda escolar é calculado com base nas recomendações da National Academy of Sciences (NAS), o que corresponde a 300-400 $\mu \mathrm{g} /$ $\mathrm{d}$ de retinol ${ }^{3}$. De acordo com os cardápios oferecidos pela creche, em torno de $75 \%$ das necessidades diárias de macro e micronutrientes para crianças menores de 6 anos eram atendidas nas três refeições ofertadas, o que significa dizer que o valor mínimo de retinol ofertado diariamente corresponde a $300 \mu \mathrm{g} / \mathrm{d}$ de retinol.

Para ser conhecida a alimentação realizada pela criança fora da creche, realizou-se o recordatório de $24 \mathrm{~h}$ no primeiro dia útil da semana, quando de seu retorno à instituição. O método foi aplicado com os pais das crianças, e a análise final das entrevistas permitiu concluir que a alimentação recebida nos finais de semana foi estimada em menos de $20 \%$ das necessidades nutricionais, incluindo vitamina $\mathrm{A}$.

\section{Avaliação antropométrica}

Todas as crianças foram pesadas em balanças eletrônicas digitais, com sensibilidade de 10g. A altura foi medida com precisão de $0,5 \mathrm{~cm}$ em infantômetros específicos. As medidas antropométricas foram registradas, em todas as crianças, no início da pesquisa e com 30, 60 e 90 dias de consumo dos flocos desidratados de abóbora. O programa Epi Info (Epi Info ${ }^{\mathrm{TM}}$ versão 6.04) foi utilizado para calcular os índices antropométricos e a frequência de distribuição. Os índices antropométricos foram padronizados de acordo com o National Center for Health Statistics (NCHS) ${ }^{20}$. Utilizou-se como indicador de risco nutricional o ponto de corte -2 escore- $Z^{21}$.

As crianças foram submetidas a exame clínico mensal completo e acurado, por médico pediatra, com atenção especial para os sinais e sintomas da carência de vitamina $A$.

\section{Estado nutricional de vitamina A}

No início do estudo, e aos 30 e 90 dias de consumo dos flocos desidratados de abóbora, foram colhidas amostras de sangue das crianças em jejum, para análise do retinol sérico pelo método espectrofotométrico ${ }^{22}$. Aleatoriamente as amostras foram reanalisadas por HPLC (High-Performance Liquid Chromatography, Cromatografia Líquida de Alta Eficiência) como controle interno ${ }^{23}$. As amostras de sangue foram coletas e imediatamente centrifugadas para extração do soro. As amostras foram transportadas ao laboratório sob refrigeração e proteção da luz, para serem analisadas imediatamente ou congeladas para análise posterior ${ }^{24,25}$.

As crianças foram submetidas ao teste da Resposta Relativa à Dose (Relative Dose Response - RDR), através do qual é coletada uma amostra de sangue em jejum e, em seguida, é oferecida à criança uma dose padrão de $1.500 \mathrm{UI}$ de retinol (Arovit ${ }^{\mathrm{MR}}$ ). Após 5 horas da primeira dose, uma nova coleta de sangue é realizada. 0 teste foi realizado no início do estudo e repetido após 90 dias de consumo dos flocos desidratados de abóbora. O teste avalia a reserva hepática de vitamina $A$, sendo que uma elevação superior a 20\% nos índices de retinol sérico, 5 horas após a administração da dose, sugere um estoque hepático de vitamina A insuficiente (RDR positiva) $)^{25,26}$.

Os dados de retinol sérico foram avaliados pela ANOVA e comparados pelo teste de Duncan, ao nível de $5 \%$ de significância, utilizando o programa Statistic for Windows 5.027.

Para a comparação do índice de rejeito das preparações com e sem os flocos desidratados de abóbora, os dados foram submetidos ao teste $t$ de Student.

\section{RES U L T A D O S}

Nas análises microbiológicas, os valores de coliformes a $45^{\circ} \mathrm{C}$, Escherichia coli, Staphylococcus aureus e bolores e leveduras foram inferiores a 
10 UFC/g (Unidades formadoras de colônia/grama). Quanto à Salmonela sp., o resultado foi de ausência em $25 \mathrm{~g}$, o que comprova a qualidade da matéria prima e a utilização de boas práticas de processamento.

O índice de rejeito médio (quantidade média de sobras de alimento no prato), de quatro medidas das preparações oferecidas às crianças, foi em torno de 10,62\% com desvio-padrão de $0,64 \%$ para as preparações com flocos, e de $10,46 \%$ com desvio-padrão de 1,30\% para preparações sem flocos. Não houve diferença estatística significativa a um nível de $5 \%$ baseado no teste $t$ de Student entre as preparações com flocos e sem flocos.

Das 97 crianças que participaram da pesquisa, apenas 2 apresentavam um peso, para a idade, inferior ao escore -2 (escore-Z). Ao longo do estudo não houve mudança no índice antropométrico das crianças (Figura 1), nem registros de doença infecto-contagiosa ou sinais clínicos de deficiência de vitamina $A$.

O nível médio de retinol sérico nas crianças aumentou de $\mathrm{M}=1,438, \mathrm{DP}=0,45 \mu \mathrm{mol} / \mathrm{L}$ (valor mínimo de $0,47 \mu \mathrm{mol} / \mathrm{L}$ e máximo de $2,79 \mu \mathrm{mol} / \mathrm{L})$, no início, para $\mathrm{M}=1,659, \mathrm{DP}=0,51 \mu \mathrm{mol} / \mathrm{L}$ (valor

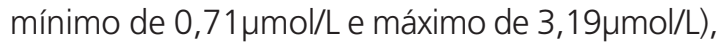
aos 30 dias, e para $M=1,928, D P=0,70 \mu \mathrm{mol} / \mathrm{L}$ (valor mínimo de $1,07 \mu \mathrm{mol} / \mathrm{L}$ e máximo de $3,62 \mu \mathrm{mol} / \mathrm{L})$, aos 90 dias. Os resultados dos três tempos diferiram entre si ao nível de $5 \%$ de significância pelo teste de Duncan. No início do estudo, $18,5 \%$ das crianças apresentavam níveis de retinol sérico abaixo do ponto de corte proposto $1,05 \mu \mathrm{mol} / \mathrm{L}^{28}$, proporção que caiu para $7,6 \%$ depois de 30 dias, e para 0\% após 90 dias do estudo.

Durante o período de consumo dos flocos desidratados de abóbora, houve uma melhora significativa e marcante no estado nutricional de vitamina $A$ das crianças que participaram do estudo, conforme observado na Figura 2 que mostra um considerável deslocamento para a direita na curva de frequência de distribuição dos valores ao longo da pesquisa.

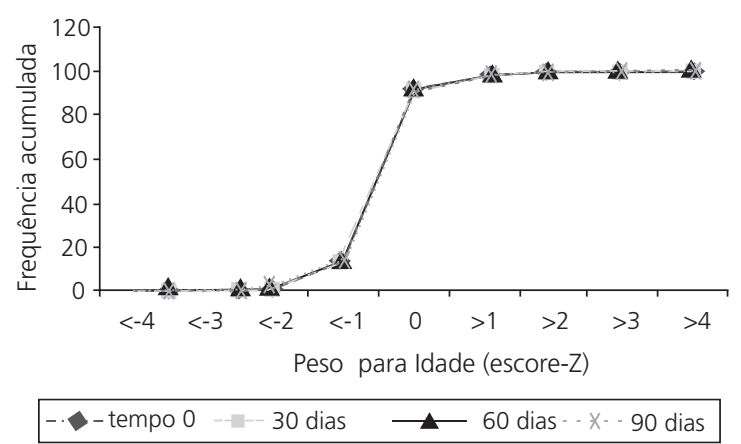

Figura 1. Frequência acumulada de peso para a idade, no início do estudo, e aos 30, 60 e 90 dias de consumo de flocos desidratados de abóbora. Creche CEAPE. Recife (PE), 2005.

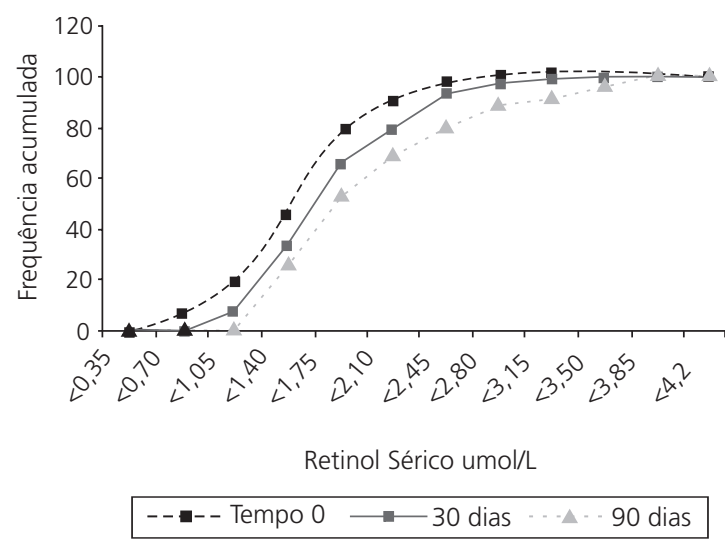

Figura 2. Frequência acumulada dos níveis de retinol sérico no início do estudo e aos 30 e 90 dias de consumo de flocos desidratados de abóbora. Creche CEAPE, Recife (PE), 2005.

O teste da RDR, positivo em 15,6\% das crianças no início do estudo, foi negativo em todas as crianças no período final do estudo (90 dias), confirmando os resultados obtidos através da análise do retinol sérico.

\section{DISCUSS Ã O}

Os resultados das análises microbiológicas estão de acordo com a legislação brasileira para produtos desidratados ${ }^{29}$.

O resultado referente à quantidade de carotenoides dos flocos, que foi utilizado no cál- 
culo da quantidade do produto oferecido às crianças, conforme descrito na metodologia, comprova que se trata de um produto processado fonte do micronutriente. Esta característica possibilita a sua utilização como alternativa no combate à hipovitaminose $\mathrm{A}$, como pode ser constatado através de estudos como os de Fernandez et al. ${ }^{16}$ e Silveira et al..$^{30}$ que utilizaram o mesmo produto em preparações que podem ser oferecidas para crianças. Fernandez et al. ${ }^{16}$ desenvolveram uma bebida láctea à base de flocos desidratados de abóbora, para ser oferecida no período de desmame, cuja formulação apresentou $115,08 \mu \mathrm{g} / \mathrm{g}$ de carotenoides totais e $80,64 \mu \mathrm{g} / \mathrm{g}$ de $\beta$-caroteno, o que correspondia a $45 \%$ das necessidades energéticas diárias das crianças e a 100\% das recomendações de vitamina A e proteínas, em $400 \mathrm{~mL}$. Silveira et al. ${ }^{30}$ desenvolveram preparações contendo inulina e flocos desidratados de abóbora, nutricionalmente adequadas para prevenir a deficiência de vitamina A, cujo conteúdo apresentava em média $94,82 \mu \mathrm{g} / \mathrm{g}$ de carotenoides totais e $75,71 \mu \mathrm{g} / \mathrm{g}$ de $\beta$-caroteno, além de possuir efeitos prebióticos quando oferecidas em pequenas refeições para crianças entre 4 e 6 anos de idade.

Com base nos resultados do índice de rejeito, foi constatado que a média de consumo das refeições com e sem flocos foi em torno de $90,0 \%$, indicando que a presença dos flocos não alterou a aceitação do alimento. Este percentual está acima do ponto de corte, em que um percentual superior a 70,0\% de aprovação indica que o produto foi bem aceito ${ }^{31}$. Em estudos anteriores, Ambrósio et al..$^{19}$ avaliaram a aceitabilidade dos flocos oferecidos no pirão de crianças, observando índice de aceitação de 95,2\%, enquanto Silveira et al. ${ }^{30}$ constataram percentual de aceitação de $70,0 \%$ para uma bebida à base de flocos de abóbora e inulina.

A avaliação antropométrica reforça o conceito de "fome oculta" da carência de vitamina $A$, quando demonstrou que se tratava de um grupo com crescimento ponderal esperado para a idade, apesar de apresentar um percentual significativo em risco nutricional de deficiência de vita- mina A. A suplementação com flocos de abóbora durante os 90 dias não interferiu, dessa forma, nos índices antropométricos (Figura 2).

Os resultados referentes à elevação dos níveis de retinol e à melhora da reserva hepática de vitamina A, nas crianças, comprovam a eficácia dos flocos desidratados de abóbora na prevenção da carência de vitamina $A$.

Estudos anteriores realizados experimentalmente já apontavam a efetividade de alimentos de origem vegetal na elevação da reserva hepática de vitamina A em ratos. Uma pesquisa realizada por Faro $^{32}$ comprovou a biodisponibilidade de carotenoides em ratos que consumiram uma dieta complementada com flocos desidratados de abóbora. De acordo com Graebner et al. ${ }^{33}$, verduras verde-escuras do Brasil (serralha - Sonchus oleraceus, bredo - Amaranthus viridis e taioba Xanthosoma sagittifolium) também são biodisponíveis em ratos. Yuyama \& Cozzolino ${ }^{34}$ constataram que ratos que consumiram uma ração suplementada com polpa de pupunha (Bactris gasipaes) apresentaram concentração significativamente maior de vitamina A no fígado quando comparados aos que receberam a dieta não suplementada.

Estudos em humanos corroboram os resultados obtidos na presente pesquisa. Mariath et al. ${ }^{8}$ ao avaliarem a atividade de vitamina A do buriti pela RDR em crianças, concluíram que ocorreu reversão de xeroftalmia e elevação de reservas hepáticas da vitamina, sugerindo a possível utilização do buriti em programas de combate à deficiência de vitamina A. Tang et al. ${ }^{9}$ concluíram que crianças chinesas alimentadas com vegetais verdes e amarelos mantiveram os níveis séricos de retinol e a reserva corporal da vitamina, favorecendo a proteção contra a deficiência de vitamina A durante as estações em que os alimentos fontes de provitamina A são escassos. Outras pesquisas constataram que carotenoides provenientes de frutas e verduras são eficazes na elevação dos níveis plasmáticos de carotenoides, indicando a relevância desses alimentos na nutrição humana ${ }^{35-37}$. 


\section{CONCLUSÃO}

Os resultados obtidos, nas condições em que foi realizada a presente pesquisa, permitem concluir que os flocos desidratados de abóbora, quando administrados em preparações comumente consumidas pela população infantil, contribuem para a elevação significativa dos níveis de retinol sérico e para a reserva hepática de vitamina A, podendo ser utilizados na prevenção da carência de vitamina $A$ em pré-escolares com idade entre 12 e 72 meses.

\section{A GRADECIMENTOS}

À Creche do Centro de Aprendizagem de Pernambuco (CEAPE) e ao Conselho Nacional de Desenvolvimento Científico e Tecnológico (CNPq).

\section{OLABORADORES}

Todos os autores participaram de todas as fases desde a concepção à redação do artigo.

\section{REFERÊ N CIAS}

1. Paiva $A A$, Rondó PHC, Goncalves-Carvalho CM, Illison VK, Pereira JA, Vaz-de-Lima LR, et al. Prevalence and factors associated with vitamin A deficiency in preschool children from Teresina, Piaui, Brazil. Cad Saúde Pública. 2006; 22(9):1979-87.

2. World Health Organization. Global prevalence of vitamin A deficiency. Geneva: WHO; 1995.

3. National Academy of Sciences. Dietary reference intakes for vitamin A, vitamin K, arsenic, boron, chromium, copper, iodine, iron, manganese, molybdenum, nickel, silicon, vanadium, and zinc. Washington (DC): National Academy of Sciences; 2001.

4. International Vitamin A Consultative Group. Conversion factors for vitamin A and carotenoids. Washington (DC): ILSI Research Foundation; 2002.

5. National Academy of Sciences. Recommended dietary allowances. $8^{\text {th }}$ ed. Washington (DC);1974.

6. Campos FM, Rosado GP. Novos fatores de conversão de carotenóides provitamínicos A. Ciênc Tecnol Aliment. 2005; 25(3):571-8.
7. Ambrósio CLB, Campos FACS, Faro ZP. Carotenóides como alternativa contra a hipovitaminose A. Rev Nutr. 2006; 19(2):233-43. doi: 10.1590/\$14 15-52732006000200010.

8. Mariath JGR, Lima MCC, Santos LMP. Vitamin A activity of buriti (Mauritia vinifera Mart) and its effectiveness in the treatment and prevention of xerophthalmia. Am J Clin Nutr. 1989; 49(5): 849-53.

9. Tang G, Gu X, Hu S, Xu Q, Quin J, Dolnikowski $\mathrm{GG}$, et al. Green and yellow vegetables can maintain body stores of vitamin $A$ in Chinese children. Am J Clin Nutr. 1999; 70(6):1069-76.

10. Noor Aziah AA, Komathi CA. Physicochemical and functional properties of peeled and unpeeled pumpkin flour. J Food Sci [Internet]. 2009 [cited 2012 Jun 16]; 74(7):S328-S333. Available from: $<$ http//www.onlilibrary.wiley.com>.

11. Kolawole OF, Olufemi TS. Effect of pretreatments on air-drying pattern and color of dried pumpkin (Cucurbita Maxima) slices. J Food Process Eng. 2010. 33(6):1129-47. doi. 10.1111/J.1745-4530.20 08.00330.

12. Purcell AE, Walter WM. Autoxidation of carotenes in dehydrated sweet potato flakes using betacarotene-14C. J Agric Food Chem. 1968; 16(4): 650-3.

13. Emenhiser C, Watkins RH, Simunovic N, Solomons $N$, Bulux J, Barrows J, et al. Packaging preservation of $\beta$-carotene in sweet potato flakes using flexible film and an oxygen absorber. J Food Quality. 2007; 22(1):63-73.

14. Sapers GM, Panasiuk O, Talley FB, Shaw RL. Flavor quality and stability of potato flakes: effects of drying conditions, moisture content and packaging. J Food Sci. 2006; 39(3):555-8.

15. Hoover MW. A process for production of dehydrated pumpkin flakes. J Food Sci. 1973; 38(1): 96-8.

16. Fernandez ZF, Guerra NB, Diniz NMA, Salgado SM, Guerra TMM, Lopes ACS, et al. Desenvolvimento de bebida láctea a base de flocos de abóbora. Arch Latinoam Nutr. 1998; 48(2):175-8.

17. Speck ML, editor. Compendium of methods for the microbiological examination of foods. Washington (DC): American Public Health Association; 1976.

18. Rodríguez-Amaya DB. A guide to carotenoid analysis in foods. Washington (DC): ILSI Press; 1999. p.41-5.

19. Ambrósio CLB, Campos FACS, Faro ZP. Aceitabilidade de flocos desidratados de abóbora. Rev Nutr. 2006; 19(1):39-45. doi: 10.1590/\$1415-5273200 6000100004 . 
20. World Health Organization. Use and interpretation of anthropometric indicators of nutritional status. Bull World Health Org. 1986; 64(6):929-41.

21. World Health Organization. Physical status: the use and interpretation of anthropometry. Geneva: WHO; 1995. Report of a WHO Expert Committee.

22. Araújo CRC, Flores H. Improved spectrophotometric vitamin A assay. Clin Chem. 1978; 24(2):386.

23. Deruyter MGM, Deleenheer AP. Determination of serum retinol (vitamin A) by high-speed liquid chromatography. Clin Chem. 1976; 22(10):1593-5.

24. Barreto-Lins MHC, Campos FACS, Azevedo MCNA, Flores $\mathrm{H}$. A re-examination of the stability of retinol in blood and serum, and effects of a standardized meal. Clin Chem. 1988; 34(11):2808-10.

25. Flores H, Campos F, Araújo CRC, Underwood BA. Assessment of marginal vitamin A deficiency in Brazilian children using the relative dose response procedure. Am J Clin Nutr. 1984; 40(6):1281-9.

26. Loerch JD, Underwood BA, Lewis KC. Response of plasma levels of vitamin $A$ to a dose of vitamin $A$ as an indicator of hepatic vitamin $A$ reserves in rats. J Nutr. 1979; 109(5):778-86.

27. Statsoft. Statistica for Windows 5.0, 1995. Computer program manual. Tulsa: Statsoft; 1997.

28. Flores H, Azevedo MNA, Campos FACS, Barreto-Lins MHC, Cavalcanti AA, Salzano A, et al. Serum vitamin A distribution curve for children aged 2-6 y known to have adequate vitamin A status: a reference population. Am J Clin Nutr. 1991; 54(4): 707-11.

29. Agência Nacional de Vigilância Sanitária. Resolução RDC $n^{\circ} 12$, de 2 de janeiro de 2001. Aprova o regulamento técnico sobre padrões microbiológicos para alimentos. Diário Oficial da União. 200110 jan; p.45-53, Seção 1.
30. Silveira KC, Brasil JA, Livera AVS, Salgado SM, Faro ZP, Guerra NB. Bebida à base de flocos de abóbora com inulina: características prebióticas e aceitabilidade. Rev Nutr. 2008; 21(3):267-76. doi: 10.1590/ S1415-52732008000300001.

31. Teixeira E, Meinert EM, Barbetta PA. Análise sensorial de alimentos. Florianópolis: UFSC; 1987.

32. Faro ZP. Aproveitamento industrial da polpa de abóbora [tese]. Recife: Universidade Federal de Pernambuco; 2001.

33. Graebner IT, Siqueira EMA, Arruda SF, Souza EMT. Carotenoids from native brazilian dark-green vegetables are bioavailable: a study in rats. Nutr Res. 2004; 24(8):671-9.

34. Yuyama LKO, Cozzolino SMF. Efeito da suplementação com pupunha como fonte de vitamina A em dieta: estudo em ratos. Rev Saúde Pública. 1996; 30(1):61-6.

35. van Het Hof KH, Tijburg LBM, Pietrzik K, Weststrate $J A$. Influence of feeding different vegetables on plasma levels of carotenoids, folate and vitamin C: effect of disruption of the vegetable matrix. $\mathrm{Br} \mathrm{J}$ Nutr. 1999; 82(3):203-12.

36. Yeum KJ, Booth SL, Sadowski JA, Liu C, Tang G, Krinsky $\mathrm{NI}$, et al. Human plasma carotenoid response to the ingestion of controlled diets high in fruits and vegetables. Am J Clin Nutr. 1996; 64(4):594-602.

37. Edwards AJ, Vinyard BT, Wiley ER, Brown ED Collins JK, Perkins-Veazie $P$, et al. Consumption of watermelon juice increases plasma concentrations of lycopene ans- $\beta$ carotene in humans. J Nutr. 2003; 133(4):1043-50.

Recebido em: 22/2/2011

Versão final reapresentada em: 27/6/2011 Aprovado em: 20/9/2011 